\title{
Uma releitura do cuidado heideggeriano a partir do primado ontológico da afetividade
}

\section{A New Reading of Heideggerian Care Departing from the} Ontological Primacy of Affectivity

DOI: $10.12957 /$ ek.2016.22773

\author{
Dra. Chiara Pasqualin \\ chiarapasqualin@hotmail.it \\ Universidade de São Paulo
}

Com base na ideia do "projeto lançado" e na análise da angústia desenvolvidas em Ser e tempo, pode-se interpretar a relação entre os dois existenciais fundamentais no sentido de um primado ontológico da afetividade (Befindlichkeit) em relação à compreensão (Verstehen). A afetividade é aquela via de acesso preliminar ao horizonte fenomenal na qual é fundada a possibilidade da compreensão. À luz desta primazia, a afetividade não constitui somente um momento estrutural do cuidado ao lado do projeto e do ser-junto-a, mas acaba por representar $o$ elemento fundamental que torna possível tanto a compreensão quanto a interpretação. Esta relação formal destacável na ontologia fundamental está presente também no pensamento heideggeriano da história do Ser. Um conceito parcialmente reformulado de Befindlichkeit não somente continua a desempenhar um papel central nas Contribuições à filosofia, mas mantém também aquela prioridade que já era reconhecível na ontologia fundamental.

PALAVRAS CHAVE Heidegger, afetividade, compreensão, cuidado, ser-junto-a 
Departing from Being and Time and, particularly, from the idea of "thrown project" and the analysis of anxiety, we argue that affectivity (Befindlichkeit) has an ontological priority over understanding (Verstehen). Affectivity is the most primordial way of access to the phenomenal horizon, therefore enabling the possibility of understanding. Considering this primacy, affectivity is not simply $a$ structural moment of care along with the other two determinations of projective potentiality and being-together-with, but it also represents the fundamental element in which understanding and interpretation are grounded. This formal relationship, which is implicit in Heidegger's fundamental ontology, is still recognizable in his later thought of the history of Being. A partially renewed concept of Befindlichkeit not only continues to play a central role in the theoretical framework of Heidegger's Contributions to Philosophy, but also maintains the same ontological primacy that can be highlighted through a close investigation of fundamental ontology.

KEYWORDS Heidegger. Affectivity. Understanding. Care. Being-together-with 
A questão da afetividade - explicitamente tematizada por Heidegger em algumas etapas fundamentais do seu percurso especulativo, mas sempre presente no fundo do seu discurso filosófico - tem recebido nos últimos trinta anos um interesse crescente. A tendência prevalente dos estudiosos tem sido oferecer uma visão geral e introdutória sobre este assunto particular ${ }^{1}$, que permaneceu por muito tempo inexplorado, apesar da amplíssima bibliografia heideggeriana. Nessa linha de pesquisa, a literatura crítica insistiu especialmente no caráter anti-dualístico da concepção heideggeriana dos fenômenos afetivos. De fato, Heidegger evita cair em contrastes simplistas, tais como, por exemplo, interior-exterior, subjetivo-objetivo, razão-sentimento, porque analisa os humores - por ele designados como Stimmungen para evidenciar o afastamento das abordagens tradicionais das emoções - apontando o caráter revelador das tonalidades afetivas, consistente no fato de que elas identificam maneiras de abertura, por meio das quais o ser-aí já está sempre relacionado com si mesmo, com os outros seres humanos, com o mundo e com a verdade do ser. Levando em conta este elemento-chave da compreensão heideggeriana do afetivo, a tradição crítica se ocupou de destacar a novidade desta perspectiva, contrapondo ao seu estudo a reconstrução dos trilhos fundamentais ao longo dos quais se moveu, num sentido diferente, a tradição metafísica. A abordagem heideggeriana tem representado, aos olhos de muitos estudiosos, uma via privilegiada para se livrar de uma filosofia por demais acostumada a negligenciar a importância da realidade afetiva, ou a subordiná-la ao elemento intelectual ${ }^{2}$.

Um ponto fundamental sobre o qual os críticos têm posto particular ênfase, é a tese heideggeriana segundo a qual existe um entrelaçamento essencial, e não meramente contingente, entre a esfera da afetividade e aquela da compreensão, entre o pensamento e os humores ${ }^{3}$. Sem querer negar esta aquisição indiscutível da reflexão heideggeriana, é possível, porém, dar um passo adiante no raciocínio para mostrar que a afetividade até mesmo revela um primado on-

1 Veja-se, sobretudo: HELD, 1991; FINK-EITEL, 1992; WEBERMAN, 1996; DE ANGELIS, 2000; MULHALL, 2002; ESCUDERO, 2010. Investigações mais amplas são oferecidas por: POCAI, 1996; KALARIPARAMBIL, 1999; FERREIRA, 2002; RODRÍGUEZ, 2003.

2 Cf., em particular: HAN, 1996; CORIANDO, 2002.

3 Cf. HAAR, 1988; STENSTAD, 1991; GANDER, 1994; CORBEIL, 1999; CAPUTO, 2001 e 2005; BORGES-DUARTE, 2012. 
tológico em relação à compreensão. Para sustentar esta leitura, é necessário analisar, em particular, a relação estabelecida entre os dois existenciais fundamentais da compreensão (Verstehen) e da Befindlichkeit em Ser e tempo.

Apontamos, nesta introdução, que o termo Befindlichkeit será aqui traduzido como "afetividade", assim como já foi proposto por alguns comentadores ${ }^{4} \mathrm{e}$ diferentemente das traduções correntes de Ser e tempo. Vertendo Befindlichkeit para "disposição" tende-se a acentuar o aspecto ôntico à custa daquele ontológico, embora haja, do ponto de vista de Heidegger, uma diferença entre a $\mathrm{Be}$ findlichkeit e o humor, a maneira particular como o homem se sente e está cada vez disposto. Por outro lado, a tradução de Befindlichkeit como "encontrar-se" acaba por generalizar o fenômeno, apontando de maneira indeterminada o caráter situado do ser-aí, mas não especificamente o lado afetivo. Contudo, o cunho e a primeira elaboração do conceito de Befindlichkeit ocorre no curso universitário do semestre de verão de 1924, em que Heidegger explora o conceito

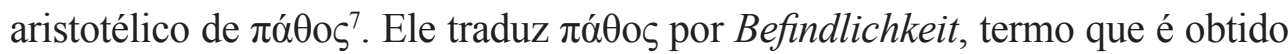
substantivando o verbo alemão sich befinden, o qual é utilizável como sinônimo de sich fühlen ${ }^{8}$. Portanto, o contexto conceitual em que se forma o termo Befindlichkeit se refere claramente ao sentir-se afetivo, o que autoriza então um estreitamento do campo semântico na tradução.

A tese relativa à primazia da afetividade em relação à compreensão, demonstrada na primeira parte deste estudo, não é explicitamente formulada por Heidegger, mas pode ser obtida a partir de suas análises. Não se pretende propor aqui uma reconstrução histórico-filosófica exata da posição heideggeriana, mas verificar se as indicações oferecidas pela sua obra permitem questionar o modelo segundo o qual o homem é, no fundo, redutível ao seu ser hermenêutico. O objetivo não é apresentar um compêndio do que Heidegger verdadeiramente pensava sobre a afetividade. Admitindo que isso seja possível, a exposição de um "Heidegger em si" seria mera verdade historiográfica "sumamente

4 Veja-se: CAPUTO, 2001; BORGES-DUARTE, 2012.

5Cf. HEIDEGGER. Ser e tempo, 2006, § 29, p. 193.

6Cf. HEIDEGGER. Ser e tempo, 2012, § 29, p. 383.

7 O conceito elaborado no curso universitário de 1924 sobre os Conceitos fundamentais da filosofia aristotélica é aplicado na conferência sobre O conceito de tempo para traduzir o termo affectio em Agostinho (Cf. HEIDEGGER. O conceito de tempo, 2008, pp. 32-33). A conferência é pronunciada no dia 25 de julho de 1924 e, portanto, pouco antes da conclusão do curso universitário que Heidegger ministrou entre o dia $1^{\circ}$ de maio e o dia 31 de julho.

8 Cf. HEIDEGGER. Grundbegriffe der aristotelischen Philosophie, GA 18, 2002, em particular, pp. 4, 163, 170 e 178. 
enfadonha" ". A tentativa é, ao contrário, re-atualizar algumas potencialidades ínsitas no pensamento heideggeriano, e no seu não-dito filosófico-teorético, a fim de desenvolvê-las numa autônoma tese interpretativa. De acordo com a posição aqui defendida, a chamada dimensão "hermenêutica", à qual pertencem a compreensão e o pensamento, a fala (Rede) e a linguagem, não esgota completamente o ser do homem. Precisamente a exploração daquela modalidade de acesso ao mundo na qual a afetividade consiste e que resulta distinta e autônoma em relação ao compreender, leva-nos a reconhecer uma outra dimensão do existir ao lado daquela hermenêutica, uma dimensão que designamos como

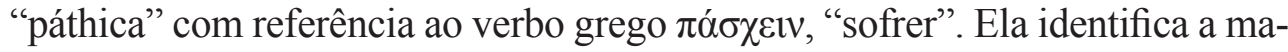
neira de acesso mais originária do homem ao "real", executada pelo abrimento, sempre lançado, da Befindlichkeit.

À luz desta perspectiva interpretativa, pretende-se destacar, na segunda parte do presente ensaio, a centralidade da afetividade dentro da estrutura tripartida do cuidado (Sorge), o qual caracteriza, como evidenciado pelo parágrafo 41 de Sein und Zeit, o ser-no-mundo na sua totalidade ${ }^{10}$. Interpretado a partir do primado da afetividade, o cuidado revela ter na Befindlichkeit o seu momento fundador. Tal papel primário da afetividade na configuração das relações recíprocas entre os momentos estruturais do cuidado não é apenas demonstrável com base em Ser e tempo, mas resulta confirmado também no contexto da obra posterior Contribuições à filosofia, que representa a primeira e mais ampla construção do pensamento da história do $\operatorname{Ser}^{11}$.

\section{A primazia ontológica da afetividade}

Como referido no parágrafo 28 de Ser e tempo, a afetividade é, juntamente com a compreensão, um dos dois modos constitutivos em que o ser-aí tem que ser o próprio "aí"12: ou seja, a afetividade é um dos dois modos em que o ser-aí se abre à dimensão multifacetada do ser. Desde o começo do quinto capítulo da primeira seção, em que é conduzida a análise detalhada dos existenciais fundamentais, Heidegger distingue afetividade e compreensão, na medida em

9 HEIDEGGER. Hinos de Hölderlin, 2004, p. 138.

10 Cf. HEIDEGGER. Ser e tempo, 2006, § 41, pp. 258-264.

11 Cf. Von HERRMANN. Wege ins Ereignis, 1994, pp. 27-29.

12 Cf. HEIDEGGER. Ser e tempo, 2006, § 28, p. 192. 
que fala de dois modos, e, ao mesmo tempo, coloca-os em conexão. Antes de considerar como se configura esta relação de distinção/conexão, é necessário ganhar um entendimento adequado dessas duas estruturas do ser-aí. Para este fim, cabe ressaltar que a noção de "faculdade" deve ser evitada por causa dos mal-entendidos que ela poderia engendrar: por um lado, um discurso sobre as "faculdades" tende a introduzir sub-repticiamente a ideia metafísica de sujeito, da qual Heidegger pretende se afastar, e, por outro, um tal discurso poderia também dar origem a uma visão fragmentária do homem, que contrasta com o sentido unitário do cuidado ${ }^{13}$.

Mais adequado ao esclarecimento e à representação da afetividade e da compreensão é o conceito de "modo (ou via) de acesso" (Zugangsweise ou Zugangsart), expressão que Heidegger utiliza em relação às determinações aristotéli-

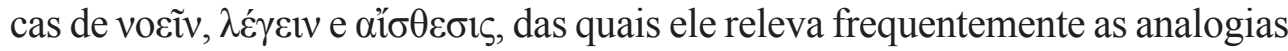
com os existenciais por ele elaborados ${ }^{14}$. De acordo com esse uso, também a afetividade e a compreensão são pensáveis como modos de acesso fundamentais, por meio dos quais o ser-aí se relaciona com o ser e, consequentemente, com a realidade ôntica. Além disso, sendo modos fundamentais em que o ser-aí se abre ao ser, afetividade e compreensão constituem dois modos - e portanto ontologicamente distinguíveis - de "abrir" (Erschließen) ou "descobrir" a realidade fenomenal: pode-se falar, respectivamente, de um abrir "páthico" e de um abrir "hermenêutico", introduzindo, porém, qualificações que o próprio Heidegger não utiliza ${ }^{15}$.

Com base nas ideias-chave de Ser e tempo, é possível interpretar a relação entre os dois existenciais fundamentais no sentido de um primado da afetividade sobre a compreensão. A leitura aqui sugerida é principalmente inspirada

13 A esse risco de mal-entendido Heidegger faz alusão numa passagem do parágrafo 60: "O cuidado, porém, no sentido de preocupação em ocupações, abrange o ser do ser-aí de modo tão originário e total que já se deve pressupor como o todo, em qualquer distinção entre atitude prática e teórica. Ele não pode ser construído a partir dessas duas faculdades através de uma dialética necessariamente destituída de fundamentos porque não fundada existencialmente" (Id., ibid., $\S 60$, p. 382, trad. modificada).

14 Cf. id., ibid., $\S 9$, p. $88 ; \S 21$, p. 148. Pense-se no trabalho de assimilação que Heidegger conduz sobre Aristóteles nos anos dos primeiros cursos de Freiburg e Marburg. Nesse sentido são imprescindíveis os vários estudos de Franco Volpi relativos à ontologização heideggeriana das determinações aristotélicas. Veja-se como estudo emblemático: Volpi, 1984.

15 Tendo presente que Heidegger reconhece um Erschließen da Befindlichkeit (cf. HEIDEGGER. Sein und Zeit, GA 2, 1977, § 29, pp. 185-186) e um verstehendes Erschließen (cf. id., ibid., § 32, p. 201), introduz-se aqui como qualificações respectivas dessas duas modalidades de "abrir" os adjetivos "páthico" e "hermenêutico". Esse último termo já tem em Heidegger um uso técnico, que é referido à maneira de descobrimento própria do interpretar (Auslegen), entendido como o desenvolvimento natural e necessário do compreender (cf. HEIDEGGER. Ser e tempo, 2006, §33, p. 220). 
na ideia de Heidegger do "projeto lançado"16 e na sua análise da angústia. A afirmação da primazia da Befindlichkeit se articula em duas teses principais: 1. a reivindicação da autonomia da afetividade; 2 . a atribuição de um papel de fundamento à afetividade em relação à compreensão. Relativamente ao primeiro ponto, pretende-se defender a ideia de que a afetividade possui uma autonomia em relação à compreensão na medida em que a afetividade não exige, para pôr em ato o seu abrir, que a compreensão seja simultaneamente executada. Esta tese deve ser entendida num sentido estritamente ontológico, isto é, do ponto de vista da distinção, feita na análise filosófica, entre estruturas diferentes e características do modo de ser dos entes humanos. Se não se tratasse de estruturas ontológicas distintas, não faria sentido que Heidegger falasse - assim como faz no curso de 1924 sobre os Conceitos fundamentais da filosofia aristotélica - da Befindlichkeit dos animais ${ }^{17}$, os quais, porém, como resulta das Lições do semestre 1929-1930, não têm compreensão alguma ${ }^{18}$. Contudo, aquilo que é possível distinguir do ponto de vista filosófico-conceitual não fica evidente se nos limitarmos à observação do que acontece normalmente em nosso existir ôntico. Na maioria das situações concretas, o abrir da afetividade é indistinguível daquele da compreensão. De fato, o ser-aí se abre ao mundo pondo em ato, no mesmo instante ôntico, a afetividade e a compreensão. $\mathrm{O}$ horizonte fenomenal ao qual o ser-aí está relacionado toma forma como resultado da interação entre os modos de abrir da afetividade e da compreensão. Portanto, levando em conta a normalidade das situações, a autonomia ôntica da Befindlichkeit é excluída, o que torna difícil defender a sua autonomia ontológica.

Todavia, há pelo menos um caso ôntico, atestado por Heidegger, que permite visualizar ônticamente a autonomia ontológica da afetividade: trata-se do caso da angústia, descrita no $\S 40^{19}$. Sabe-se que na angústia ocorre um repentino colapso do dado fenomenal na insignificância (Unbedeutsamkeit) ${ }^{20}$. Sendo que a significância como estruturação significativa da realidade é o resultado da atividade do processo da compreensão, o fato de que, na angústia, os fenômenos se manifestam como insignificantes pode ser lido como indício de uma momentânea regressão ou inatividade da função hermenêutica própria da

16 Id., ibid., § 31, p. 208 (trad. modificada).

17 Cf. HEIDEGGER. Grundbegriffe der aristotelischen Philosophie, pp. 53-55.

18 Cf. HEIDEGGER. Die Grundbegriffe der Metaphysik. Welt - Endlichkeit - Einsamkeit, GA 29/30, 1983, p. 360 .

19 Também a descrição da angústia feita em O que é metafísica? permite chegar aos mesmos resultados teóricos. Cf. HEIDEGGER. O que é a Metafísica?, 2004.

20Cf. HEIDEGGER. Ser e tempo, 2006, § 40, p. 253. 
compreensão ${ }^{21}$. Isso não significa que de repente a compreensão desapareça: isso seria um absurdo porque ela é um existencial fundamental do ser-aí que o define na sua constituição ontológica. Pode-se descrever de maneira mais adequada essa circunstância por meio dos conceitos aristotélicos de potência e ato: na angústia a compreensão passa do seu estar concretamente executada para um estado de simples potência. Ela se retrai - no sentido dos verbos alemãos zurücktreten e sich entziehen - deixando que a afetividade passe para o primeiro plano e seja a única autora do movimento de abertura. Contra a nossa tese poder-se-ia objetar que na angústia o ser-aí ainda compreende, na medida em que entende o fato de não estar compreendendo mais. Mas na verdade essa compreensão surge só depois que a angústia desvanece. Se o ser-aí já comprendesse no momento do manifestar-se da angústia, ele realizaria o ser-para-a-morte (e o querer-ter-consciência) já naquele instante ôntico, o que não é o nosso caso, porque Heidegger acredita qua a angústia nos leva apenas ao encontro da possibilidade de existir autenticamente, sem, contudo, já se configurar como a decisão de anticipar a morte ${ }^{22}$.

Embora o ser-aí angustiado se encontre nessa condição de suspensão ou paralisia da sua atividade hermenêutica, ele continua a estar aberto à realidade e, até mesmo, ganha um contato privilegiado com ela ${ }^{23}$. Se na angústia, então, um abrimento ao dado fenomenal ainda ocorre, e se o compreender é temporariamente suspenso, aquele abrimento em ato só pode ser oferecido pelo outro existencial fundamental: pela afetividade. A angústia é, portanto, um raro caso ôntico que demonstra como o abrimento da afetividade é, em princípio, autônomo em relação àquele do compreender, isto é, o abrimento "páthico" não exige, para ser executado, que também a compreensão esteja em andamento. Ao contrário, da análise heideggeriana resulta claramente que o compreender não pode

21 A abertura do mundo como significância ou complexo ordenado de referências entre entes e possibilidades existenciais é tarefa da compreensão (cf. id., ibid., § 18, pp. 137-138). A descoberta de um certo ente como significativo (bedeutsam ou bedeutungsmäßig) é o resultado do ulterior e necessário desenvolvimento da compreensão na interpretação (Auslegung), a qual focaliza apenas um nó da rede global das referências, preliminarmente abertas pela compreensão (cf. id., ibid., § 32, pp. 209-210; §34, pp. 223-224). O fato de que o mundo cai na insignificância - ou seja que a angústia descobre o "'algo' mais originário" (cf. id., ibid., § 40, p. 253), isto é, a possibilidade e a fonte da significância - implica que, naquele instante ôntico, deve estar suspensa também a auto-compreensão, ou seja a outra modalidade de compreensão além da compreensão do mundo (Weltverstehen). De fato, o Weltverstehen sempre pressupõe o projeto de possibilidades, entendidas como aquilo "em-vista-de-que" algo é descoberto como significativo.

22 Isso fica bem claro na distinção heideggeriana entre a temporalidade própria da angústia e aquela da compreensão autêntica. Cf. id., ibid., § 68b, p. 430: "A angústia, porém, também não implica um assumir que retoma a existência na decisão. A angústia, bem ao contrário, recoloca o estar-lançado enquanto possível de ser retomado".

23 Cf. id., ibid., § 39, p. 248, onde Heidegger define a angústia como "uma das possibilidades de abertura mais abrangentes e mais originárias". 
prescindir da afetividade: sempre, quando estou compreendendo, encontro-me, ao mesmo tempo, aberto de maneira afetiva à realidade ${ }^{24}$.

Juntamente com o aspecto de autonomia da afetividade, a nossa tese acerca do primado desse existencial pretende indicar também o papel de fundamento que a Befindlichkeit desempenha. Nesse contexto, utilizamos o termo "fundamento" (Grund) como sinônimo de "condição de possibilidade". Conforme esclarecido nos Seminários de Zollikon, um elemento $a$ é fundamento de $b$, quando $b$ não pode ser sem $a^{25}$. Do caráter de autonomia da afetividade deduz-se que a compreensão não pode ser fundamento da afetividade, porque essa última pode conceder a sua abertura sem que o compreender seja executado. E vice-versa, a ideia heideggeriana do projeto lançado permite formular a tese oposta: ou seja, que é a afetividade que possibilita a compreensão. Em termos formais, o estar-lançado do projeto indica o fato de que a compreensão não é uma produção a partir do nada, mas revela-se sempre como o acolhimento e a elaboração de algo já dado. Se se aceita a nossa proposta de interpretar o Verstehen como uma Zugangsweise, o caráter ontologicamente lançado do compreender deverá significar que o modo de acesso hermenêutico ao ser e à realidade ôntica sempre se baseia em algo já dado e descoberto. Esse dado preliminar, que é ontologicamente pressuposto pela compreensão, não pode que consistir naquilo a que o outro modo de acesso fundamental, a afetividade, abre. Na sua atividade formadora de significância, o compreender, então, assume e elabora o dado fenomenal que foi anteriormente descoberto pela via da afetividade.

Essa circunstância está exposta emblematicamente na relação estabelecida em Ser e tempo entre angústia e compreensão autêntica. $\mathrm{O}$ querer-ter-consciência enquanto compreensão autêntica é a elaboração e a assunção daquilo que a afetividade revela na condição ôntica da angústia. O que a compreensão autêntica entende é, para Heidegger, "o ser-culpado originário" 26 , que não indica o fato de ser responsável por uma determinada falta ôntica, mas a finitude característica do nosso ser, evidente, em seu grau máximo, no fato de estarmos-lançados à morte. Contudo, a descoberta da mortalidade como limite

24 Heidegger acredita que o compreender é sempre afetivo (befindlich) e, portanto, nele deve sempre estar em ato o abrimento da Befindlichkeit. Cf. HEIDEGGER. Ser e tempo, 2012, § 31, pp. 410-411; § 51, pp. 696-697; § 53, pp. 728-729.

25 Ver HEIDEGGER. Seminários de Zollikon, 2001, p. 43: "Não há vazio sem livre. O vazio é fundamentado no livre. Que relação de fundamento é essa? [...] Um fundamento (Grund) factual diz que uma coisa não pode ser sem outra. Vazio não pode ser sem 'livre'; 'livre', isto é, ocupável é mais original do que 'vazio"'.

26 HEIDEGGER. Ser e tempo, 2012, § 58, p. 785. 
constitutivo da facticidade humana ocorre precisamente na angústia ${ }^{27}$. Portanto, a compreensão autêntica, que é, ao mesmo tempo, querer-ter-consciência e decisão antecipadora (vorlaufende Entschlossenheit) ${ }^{28}$, é a assunção do dado da finitude revelado pela angústia. Esta última, porém, já não é a compreensão autêntica, caso contrário Heidegger não teria distinguido a temporalidade própria da angústia e aquela da compreensão autêntica ${ }^{29}$. A angústia se limita a revelar ou pre-sentir a possibilidade da autenticidade, sem ser, contudo, sua já efetiva atuação, o que ocorre apenas na compreensão como decisão antecipadora.

A relação que Heidegger estabelece entre angústia e compreensão autêntica visualiza, a nível ôntico, a tese ontológica segundo a qual a afetividade é o fundamento da compreensão. A análise heideggeriana deixa claro que a angústia é a condição de possibilidade da compreensão autêntica. Sendo que, contudo, na angústia ocorre apenas o abrimento da afetividade, aquilo que possibilita a compreensão autêntica é, em última análise, a própria Befindlichkeit. O caso da angústia "ilustra" de maneira ôntica a maneira como sempre interagem, do ponto de vista ontológico, os dois existenciais fundamentais: a compreensão é a assunção e a elaboração do dado fenomenal preliminarmente aberto e descoberto pela afetividade. Nessa perspectiva, a afetividade é o "a priori" ontológico da compreensão. Aqui retomamos o sentido de aprioridade que o próprio Heidegger assume no uso que ele faz da noção de "perfeito a priori" ${ }^{30}$. Do seu ponto de vista, a interpretação de um certo ente na sua possível aplicação é aquele "perfeito a priori" que possibilita a utilização concreta desse ente. Se, por exemplo, eu não tivesse interpretado os sapatos como utilizáveis para caminhar, não poderia colocá-los e passear. Por outro lado, é claro que a aprioridade não implica uma sucessão temporal, como se antes eu interpretasse e só depois, num segundo instante cronológico, pudesse caminhar. Trata-se apenas de uma relação em que um elemento $a$ possibilita um elemento $b$, embora essa condição prévia não possa ser facilmente intuída a partir dos dados ônticos. O

27 Cf. HEIDEGGER. Ser e tempo, 2006, § 50, p. 326.

28 Cf. id., ibid., § 60, p. 382: "A decisão, porém, delimita a estrutura existencial do poder-ser próprio, testemunhado na consciência, isto é, do querer-ter-consciência». Cf. também id., ibid., $\S 62$, p. 389: "É a decisão antecipadora que compreende o poder-ser-culpado propriamente e totalmente, ou seja, originariamente" (trad. modificada).

29 A temporalidade da compreensão autêntica é descrita no $§ 68$ a como antecipar (Vorlaufen), instante (Augenblick) e retomada (Wiederholung). Ao contrário, a temporalidade da angústia, descrita no $\S 68 \mathrm{~b}$, apenas nos põe diante da possibilidade do antecipar, do instante e da retomada. Cf. id., ibid., § 68a-68b, pp. 421-433. Veja-se, em particular, id., ibid., § 68b, p. 430: "Embora a atualidade da angústia se mantenha, ela ainda não possui o caráter do instante, que se temporaliza na decisão. A angústia só conduz para o humor de uma decisão possível".

30 Cf. id., ibid., § 18, p. 135. 
mesmo sentido formal de aprioridade pode ser atribuído à afetividade em relação à compreensão, sendo que a primeira possibilita a segunda oferecendo-lhe o dado preliminar sobre o qual a compreensão exerce a sua atividade.

A autonomia e a aprioridade ontológica da afetividade já evidenciam, por elas mesmas, que a afetividade é uma estrutura distinta da compreensão. Além disso, a diferença entre os dois existenciais também emerge quando se considera a maneira pela qual o abrimento é colocado em ato por cada um desses existenciais: por um lado, a afetividade é uma abertura na qual o ser-aí se encontra lançado e que lhe é doada independentemente da sua iniciativa ${ }^{31}$; por outro, o abrimento da compreensão possui um caráter de projeto $^{32}$ e implica, portanto, o envolvimento ativo do ser-aí. Enfim, os dois existenciais podem ser diferenciados dependendo da maneira como o horizonte fenomenal se manifesta para cada um deles. Se, de fato, afetividade e compreensão são concebidas como duas Zugangsweisen, também a elas se aplica o simples princípio metodológico segundo o qual "o ente pode se mostrar por si mesmo de várias maneiras, segundo sua via e modo de acesso"33. Temos, então, que indicar em que sentido o horizonte fenomenal se mostra diferente segundo a via de acesso "páthica" e aquela hermenêutica. Levando em conta o caso emblemático da insignificância revelada pela angústia - condição na qual só o existencial da afetividade está em ato - pode-se avançar a ideia de que a realidade fenomenal se manifesta ao modo de acesso afetivo num sentido ainda não-significativo, ou seja: pré-significativo. Os fenômenos se manifestam ao modo de acesso "páthico" como dados experimentáveis, os quais interagem em cada caso com a existência no nível afetivo, mas ainda não significativos (no sentido da palavra bedeutsam ${ }^{34}$ ), isto é, ainda não ordenados dentro de um complexo de significados e relações entre possibilidades existenciais. Para designar a maneira como se manifestam os fenômenos ao abrir "páthico", introduz-se aqui a expressão "presença pré-significativa" ${ }^{35}$. Diferentemente, a realidade fenomenal aberta pela com-

31 Cf. id., ibid., § 29, p. 194: "A expressão estar-lançado deve indicar a facticidade do estar-entregado" (trad. modificada).

32 Cf. id., ibid., § 31, p. 205: "compreender possui a estrutura existencial que chamamos de projeto".

33 Id., ibid., § 7a, p. 67.

34 Trata-se de um conceito central do curso do semestre extraordinário de guerra de 1919: HEIDEGGER. Die Idee der Philosophie und das Weltanschauungsproblem. GA 56/57, 1987.

$35 \mathrm{O}$ conceito aqui introduzido da "presença pré-significativa" não deve ser confundido com a noção da simples presença (Vorhandenheit). Essa última se manifesta apenas a um entendimento teorético abstrato, que não é originário, mas sempre derivado de uma suspensão da visão prática que dirige habitualmente o nosso comportamento ôntico. 
preensão se mostra como uma totalidade articulada de significados. Pode-se, portanto, concluir que a compreensão estrutura ou forma em termos significativos aquilo a que a afetividade preliminarmente abre, experimentando-o num sentido "páthico" e pré-significativo ${ }^{36}$.

Neste ponto do nosso raciocínio, uma pergunta poderia surgir espontaneamente: como se concilia a tese da prioridade da afetividade sobre o compreender com aquela heideggeriana da "igualdade originária" (Gleichursprünglichkeit) entre tais estruturas ${ }^{37}$ ? Para responder a essa pergunta, é necessário distinguir dois significados possíveis que o intérprete poderia atribuir ao termo heideggeriano gleichursprünglich. Um primeiro sentido deixa-se deduzir do parágrafo 28 de Ser e tempo, no qual o filósofo afirma:

a impossibilidade de se derivar o que é originário não exclui uma variedade multiforme de características ontológicas constitutivas. Quando elas se mostram, são igualmente originárias do ponto de vista existencial. O fenômeno da igualdade originária dos momentos constitutivos foi, muitas vezes, desconsiderado na ontologia, em consequência de uma tendência metodológica incontrolável para comprovar a proveniência de tudo e de todos a partir de um "fundamento primordial” único e simples ${ }^{38}$.

No contexto do qual a passagem é tirada, Heidegger pretende mostrar como o fenômeno do ser-em, com o qual ele designa a constituição do ser-aí, longe de representar uma estrutura decomponível em partes, isto é, um todo entendido como soma ( $\tau$ ò $\pi \tilde{\alpha} v)$, constitui, ao contrário, um inteiro (no sentido do ö $\lambda o v$ ), cujos componentes não admitem subtração ou adição posterior. Portanto, os vários elementos que formam o inteiro do ser-em não são redutíveis às partes

36 Uma implicação da nossa tese é a anterioridade ontológica da afetividade também em relação à fala (Rede). Sendo que a fala é a função por meio da qual o compreendido se articula em significados, ela é parte integrante do processo hermenêutico, graças ao qual o horizonte fenomenal toma a forma da significância. Se, porém, seguindo o nosso raciocínio, a afetividade abre a um horizonte ainda pré-significativo, isso implica que no abrir da Befindlichkeit não está já integrada a função da fala. Só quando o dado originário aberto pela afetividade é assumido pela compreensão, ele pode chegar à estruturação discursiva. Para uma discussão detalhada deste assunto ver: PASQUALIN. Il fondamento "patico"dell ermeneutico, 2015, em particular pp. 247-266.

37 Cf. HEIDEGGER. Ser e tempo, 2006, § 28, p. 192; § 31, p. 202.

38 Id., ibid., § 28, p. 190. 
de uma soma, as quais podem faltar sem por isso comprometer a natureza do inteiro. No caso dos momentos do inteiro, temos a ver com componentes necessárias, que, cada uma delas tendo igual direito, tornam possível a subsistência do inteiro. O termo gleichursprünglich serve para indicar a relação existente entre as partes de um inteiro assim entendido.

Nesse primeiro sentido, aludido na passagem citada, afetividade e compreensão são "igualmente originárias" na medida em que ambas constituem partes imprescindíveis do inteiro existencial e não são estruturas deriváveis uma da outra. Desde o momento em que o ser-aí vem ao mundo, ele dispõe de ambas essas estruturas e não se pode dizer que uma se produza a partir da outra numa fase posterior do desenvolvimento do indivíduo. Se se assume a noção de "igualdade originária" neste primeiro sentido mencionado, ela é perfeitamente compatível com a nossa tese. Afetividade e compreensão são estruturas distintas, com modos de abrimento próprios, mas igualmente necessárias para definir o ser-aí na sua constituição ontológica. Nesse sentido, poder-se-ia falar, sem contradição, de uma anterioridade ontológica da afetividade dentro de uma relação de "igualdade originária" entre os dois existenciais fundamentais. Há, por outro lado, uma segunda possibilidade interpretativa da noção de "igualdade originária". Não levando em conta a passagem mencionada, tal noção poderia ser entendida pelo intérprete de maneira mais literal como a afirmação de que os dois existenciais fundamentais possuem um mesmo grau de originariedade. Se se toma a noção de Gleichursprünglichkeit neste segundo sentido mencionado, ela não pode ser conciliada com a nossa tese. Do ponto de vista de Heidegger, o elemento que se constitui como fundamento e que possui, portanto, uma anterioridade ontológica, é sempre caracterizado por um maior grau de originariedade ${ }^{39}$.

Antes de prosseguir, cabe lembrar e acentuar a distinção entre afetividade (Befindlichkeit) e tonalidade afetiva (Stimmung). Essa distinção, sugerida nas primeiras linhas do parágrafo $29^{40}$, é baseada na distinção heideggeriana entre ontológico e ôntico. A afetividade é aqui apresentada como a estrutura ontológica correspondente à concreta disposição ôntica. Agora, porém, o ontológico não deve ser entendido como a essência geral comum aos vários fenômenos ônticos:

39 Na passagem já mencionada dos Seminários de Zollikon em que Heidegger esclarece o que é uma relação de fundamento, ele salienta também que o elemento chamado "fundamento" de uma coisa é sempre mais originário do que essa última. Cf. HEIDEGGER. Seminários de Zollikon, 2001, p. 43.

40 Cf. HEIDEGGER. Ser e tempo, 2006, § 29, p. 193: "O que indicamos ontologicamente com o termo afetividade é, onticamente, o mais conhecido e o mais cotidiano, a saber, o humor, o estar afinado num humor" (trad. modificada). 
essa seria uma conceituação errada - típica da metafísica ${ }^{41}$. A afetividade não é, portanto, uma representação abstrata que sintetiza as características comuns dos humores. A afetividade é, ao contrário, aquela abertura primária à realidade, que funda a possibilidade do humor ôntico, no qual é configurado um modo de interação particular, de acordo ou dissonância, entre a existência e a realidade fenomenal. Resumindo, a afetividade é o pressuposto ontológico do humor particular. Pode-se observar, contudo, que o uso do termo Befindlichkeit em Ser e tempo poderia levar a minimizar a diferença há pouco mencionada e a confundir os planos: Heidegger se refere à angústia e ao medo em termos de Befindlichkei$t e n^{42}$, embora a definição mais própria deles seria aquela de Stimmungen.

Tendo presente esta distinção, concentremo-nos agora em algumas afirmações contidas em Ser e tempo que parecem refutar a nossa tese da primazia da afetividade. Tome-se, como exemplo, essa passagem emblemática: «A Befindlichkeit sempre possui a sua compreensão» ${ }^{43}$. Ou considere-se a afirmação análoga: «Toda Befindlichkeit é compreensiva» ${ }^{44}$. Estas indicações poderiam sugerir a ideia de que o abrir da afetividade não seja, no fundo, outra coisa do que o próprio compreender e que, portanto, a afetividade não seja uma estrutura distinguível nem autônoma em relação à compreensão. Contudo, antes de chegar a esta conclusão, é preciso verificar o sentido que o termo Befindlichkeit possui nestas proposições. O uso das expressões je e jede, em que é aludida a variabilidade característica dos fenômenos ônticos, deixa-nos inferir que o termo Befindlichkeit não é aqui utilizado no seu sentido próprio, mas como sinônimo de Stimmung. Portanto, o significado geral desses enunciados é afirmar que a tonalidade afetiva particular está sempre conectada com uma certa compreensão, a qual muda dependendo do humor, particular a cada vez, que a permeia. Ora, esta conexão humor-compreensão pode se configurar, a nosso ver, em duas maneiras diferentes. A situação ôntica mais habitual é aquela na qual humor e compreensão se apresentam como um fenômeno unitário. Seja quando se diz que a tonalidade afetiva é "compreensiva", seja quando se afirma que "o compreender está sempre afinado pelo humor (gestimmt)"

41 Heidegger recusa a associação entre o seu conceito de "ontológico" e a determinação metafísica de Koıvóv, entendido como aquilo que é mais geral e comum aos vários entes, em: HEIDEGGER. Contribuições à filosofia, 2014, § 107, p. 202.

42 Cf. HEIDEGGER. Ser e tempo, 2006, § 30, p. 200; § 40, p. 250.

43 Id., ibid., § 31, p. 202 (trad. modificada). Cf. HEIDEGGER. Sein und Zeit, § 31, p. 190: "Befindlichkeit hat je ihr Verständnis".

44 HEIDEGGER. Ser e tempo, 2006, § 68, p. 421. Cf. HEIDEGGER. Sein und Zeit, § 68, p. 444: "Jede Befindlichkeit ist verstehend".

45 HEIDEGGER. Ser e tempo, 2006, § 31, p. 202. 
indicar a mesma coisa, isto é, a circunstância normal e mais frequente na qual o ser-aí, que sempre se encontra num estado de ânimo, ao mesmo tempo compreende, isto é, possui uma visão específica do seu horizonte mundano, a qual é, por sua vez, determinada pela Stimmung vivenciada.

Contudo, a afirmação "a tonalidade afetiva sempre possui a sua compreensão" é interpretável também diferentemente, ou seja, da forma seguinte: a experiência da Stimmung produz uma nova compreensão, mas este entendimento ocorre apenas a posteriori. Em outras palavras, estamos aqui supondo que haja Stimmungen, sem dúvida muito raras, nas quais a compreensão está temporariamente suspensa. A angústia, descrita por Heidegger, representaria, em nosso entendimento, um desses casos. Trata-se de tonalidades afetivas que certamente dão origem a uma compreensão, mas isso acontece só depois que a tonalidade perde a sua inicial força perturbadora. Nessa segunda circunstância, a relação da Stimmung com o Verstehen não é negada, mas apenas diferida.

\section{Afetividade e cuidado}

Como ilustrado no parágrafo 41, compreensão e afetividade, que indicam, respectivamente, o projeto e o estar-lançado, constituem os dois primeiros momentos do cuidado ao lado do "ser-junto-a" (Sein-bei $)^{46}$. Com esse terceiro momento Heidegger se refere àquela visão interpretativa preliminar que guia o nosso comportamento ôntico com os entes intramundanos ${ }^{47}$. Em outras palavras, o terceiro momento do cuidado é identificável com o existencial da interpretação (Auslegung), a qual, no parágrafo 32, é considerada como a elaboração da compreensão $0^{48}$. A interpretação se articula em três modalidades principais, dependendo se ela é direcionada ao próprio ser, ao que é utilizável (zuhanden), ou ao outro ente existente. Quanto à interpretação do próprio ser, ela é designada como "transparência" (Durchsicht) e indica o movimento no qual o ser-aí busca o conhecimento de si e das suas possibilidades de maneira, antes de tudo,

46 Cf. id., ibid., § 41, pp. 258-260.

47 Isso é bem evidenciado por: Von HERRMANN. Hermeneutische Phänomenologie des Daseins, v. 3, 2008, pp. 190-206.

48 Cf. HEIDEGGER. Ser e tempo, 2006, § 32, p. 209. 
pré-reflexiva ${ }^{49}$. Além disso, Heidegger distingue a circunvisão $(U m s i c h t)^{50}$, isto é, a interpretação do ente utilizável no seu específico significado para os nossos projetos, da consideração (Rücksicht $)^{51}$, que orienta o nosso cotidiano relacionamento com outros seres humanos, os quais também se projetam em possibilidades sempre entrelaçadas com as nossas.

Entre os momentos estruturais do ser-junto-a e do compreender é reconhecível aquilo que von Herrmann define como uma "disparidade de origem" (Ursprungsgefälle) ${ }^{52}$, a qual consiste no fato de que a compreensão é condição de possibilidade do ser-junto-a e é, portanto, mais originária do que esse último. Uma exemplificação emblemática dessa circunstância é oferecida pelas análises conduzidas nos parágrafos 15-18 de $\operatorname{Ser}$ e tempo ${ }^{53}$, nos quais se mostra que a ocupação com um determinado ente, o Besorgen, está sempre fundada na compreensão do mundo. A circunvisão seria impossível sem uma preliminar compreensão do complexo de referências que conectam os entes do nosso mundo circundante. Embora em Ser e tempo seja tematizada sobretudo a circunvisão, pode-se acrescentar, integrando a análise heideggeriana, que também a transparência e a consideração se baseiam numa prévia compreensão. De fato, elas pressupõem o projeto de si, a compreensão do mundo e o entendimento do modo de ser dos vários entes encontrados. A interpretação de si a partir das possibilidades agarradas pressupõe a capacidade de me projetar, de dar uma estruturação ao mundo conforme aos meus propósitos e de entender o modo de ser dos entes que são encontrados no espaço de realização da minha existência. Por outro lado, eu posso interpretar os outros seres existentes só na medida em que eu também existo como projeto dentro de um mundo e na medida em que reconheço aqueles entes que têm o mesmo modo de ser que o meu. Resulta, assim, estar confirmada a ideia segundo a qual o momento do ser-junto-a, nas suas várias modalidades interpretativas, é fundado na compreensão.

Todavia, levando em conta os resultados expressos na primeira parte deste estudo, é possível tirar uma consequência relevante para o nosso raciocínio. Se a interpretação, que coincide com o momento do ser-junto-a, está enraizada na compreensão, essa última, por sua vez, está fundada na afetividade. Disse-

49 Cf. id., ibid., § 31 , p. 207.

50 Cf. id., ibid., § 15, p. 117.

51 Cf. id., ibid., § 26, p. 179.

52 Veja-se, em particular, Von HERRMANN. Hermeneutische Phänomenologie des Daseins, v. 3, 2008, pp. 16 e 22 .

53 Cf. HEIDEGGER. Ser e tempo, 2006, §§ 15-18, pp. 114-140. 
-se que a interpretação pressupõe uma tripla compreensão, isto é, o projeto de si, a compreensão do mundo e o entendimento do modo de ser dos entes. Ora, cada uma dessas formas de compreensão é possibilitada pelo abrir originário da afetividade. Ela descobre preliminarmente o âmbito do ser de uma maneira ainda não significativa: revela o nosso ser como pura facticidade, o mundo como horizonte fenomenal circundante ainda não formado em significados e os entes no simples fato surpreendente do seu ser e de não ser nada. Esse dado fenomenal, o “"algo” mais originário" ${ }^{4}$, preliminarmente aberto pela afetividade, é oferecido à compreensão que o estrutura em termos significativos a partir do projeto de possibilidade ${ }^{55}$. Considerando que o presupposto da interpretação consiste numa tripla compreensão que se baseia no abrir "páthico", pode-se concluir que o ser-junto-a é, em última análise, possibilitado pela afetividade. Para poder interpretar um determinado ente, existente ou não-existente, deve-se já ter descoberto o seu dar-se pré-significativo pela via de acesso da afetividade. $\mathrm{O}$ abrimento afetivo ao ente é mais originário do que o desvelamento próprio da interpretação. Como já repetimos, o discurso aqui conduzido se coloca num plano ontológico e não ôntico. Se nós olhamos para os comportamentos concretos habituais, não se pode distinguir neles o momento do abrimento afetivo do movimento interpretativo. Contudo, é legítimo perguntar-se como é que as estruturas do nosso ser interagem para que a realidade torne-se manifesta a nós.

Resumindo essas considerações necessariamente sintéticas, pode-se ressaltar que no contexto da ontologia fundamental a afetividade não é apenas um momento do cuidado, mas o seu momento fundamental. O que define o cuidado no seu sentido primário não é, portanto, o processo por meio do qual o ser-aí interpreta os entes a partir de uma prévia compreensão, mas a imediata abertura ou exposição afetiva do ser-aí ao dado fenomenal originário, isto é, ao fato de que algo é e que o seu ser nos afeta. Antes de indicar a relação hermenêutico-interpretativa da existência com o horizonte fenomenal, o cuidado indica o fato de que o ser-aí se encontra passivamente exposto ao âmbito do ser pelo medium da afetividade. Relido a partir do primado da afetividade, o cuidado heideggeriano mostra-se como não perfeitamente equivalente, nem simplesmente redutível ao processo hermenêutico da compreensão-interpretação. E nem a afetividade pode ser identificada simplesmente com o humor particular que permeia e determina a compreensão e que, na maioria dos casos, é inseparável e indistinguí-

54 Id., ibid., § 40, p. 253.

55 Uma análise de como o abrir "páthico" revela as regiões do ser e oferece o dado preliminarmente aberto à elaboração da compreensão, é desenvolvida em: PASQUALIN. Il fondamento "patico" dell'ermeneutico, 2015, pp. 199-207 e pp. 237-247. 
vel dessa mesma compreensão formando com ela um fenômeno unitário. Uma tal redução da Befindlichkeit à Stimmung acabaria por reabsorver o momento da afetividade naquele da compreensão. A afetividade seria, de fato, a simples coloração sentimental da compreensão. Na verdade, a tese que aqui nós propomos vai na direção oposta: ou seja, mostrar que o existir humano não é redutível ao processo hermenêutico, mas revela um fundamento pré-hermenêutico, que consiste no abrimento "páthico" ou afetivo. Não nos limitamos a dizer que a compreensão sempre tem uma tonalidade afetiva, estando imbuída de humor até mesmo na especulação mais abstrata, mas sugerimos que a compreensão não é a única fonte da nossa experiência.

Nessa perspectiva, a leitura levinasiana do cuidado heideggeriano nos parece problemática. Em primeiro lugar, não é possível identificar tout court o cuidado com a compreensão, assim como faz Lévinas no seu ensaio juvenil sobre Ser e tempo intitulado Martin Heidegger et l'ontologie ${ }^{56}$. Neste breve texto de 1932, Lévinas está convencido de que Ser e tempo estabeleça uma equivalência perfeita entre existir e compreender o ser. Portanto, do seu ponto de vista, também a angústia é compreensão, uma compreensão que ele identifica, de maneira ainda imprecisa, com o cuidado. Também num ensaio posterior de 1940, Lévinas toma como certa a primazia da compreensão em Ser tempo, de modo que entende o segundo momento do cuidado, a facticidade, num sentido restrito, isto é: como a indicação da pré-compreensão permeada de tonalidades afetivas na qual já nos encontramos sempre ${ }^{57}$. Partindo deste entendimento do cuidado à luz do papel dominante do Verstehen, Lévinas chegará, nas obras mais maduras, a criticar a noção heideggeriana do cuidado por se tratar de um movimento substancialmente auto-referencial que suprime a transcendência da alteridade ${ }^{58}$. $\mathrm{Na}$ verdade, como foi destacado, a afetividade ocupa um lugar fundamental na estrutura do cuidado: o momento do projeto de si, que, sem dúvida, pertence ao cuidado, é possibilitado por uma preliminar exposição passiva do homem à alteridade, seja à estranheza do próprio ser, seja à alteridade do ser dos entes encontrados. Em várias passagens da sua obra, Lévinas demostra estar reduzindo

56 Cf. LÉVINAS. Martin Heidegger et l'ontologie, 1967.

57 Cf. LÉVINAS. L'ontologie dans le temporel, 1967.

58 Que o ser-aí heideggeriano seja dobrado sobre si mesmo é atestado, segundo Lévinas, pelo fato de que o Dasein é primeiramente angustiado pela própria morte e incapaz de sentir um autêntico medo pelo outro (Cf. LÉVINAS. Notes sur le sens, 1982, pp. 245-247). Segundo Lévinas, apenas a transcendência, entendida por ele como abertura responsável ao outro homem, pode quebrar a lógica do cuidado pelo próprio ser, o conatus essendi do sujeito. Cf. LÉVINAS. Transcendance et intellegibilité, 1984, p. 26. 
o conceito de Befindlichkeit ao sentido ôntico da tonalidade afetiva ${ }^{59}$. Isso não lhe permite valorizar o conceito de Befindlichkeit nem questionar a sua impressão geral de que o cuidado seria posto sob o domínio da compreensão. Uma leitura da Befindlichkeit, como aquela que é sugerida neste ensaio, permite não somente rever a crítica levinasiana do cuidado, mas abriria também o caminho para uma aproximação entre as perspectivas de Heidegger e Lévinas, apesar das graves acusações que o segundo endereça ao primeiro. O que permitiria esta aproximação entre os dois autores seria precisamente um novo entendimento do conceito heideggeriano de Befindlichkeit, o qual poderia ser posto num diálogo frutífero com a concepção levinasiana de affectivitét ${ }^{60}$.

O papel fundador da afetividade relativamente aos outros dois momentos do cuidado, aparece mantido também no contexto do pensamento heideggeriano da história do Ser, o qual é configurado pela primeira vez e de maneira mais ampla nas Contribuições à filosofia. Para mostrar a validade da nossa tese também no horizonte teórico das Contribuições, devemos enfrentar uma primeira dificuldade, isto é, a ausência do termo Befindlichkeit desta segunda obra capital de Heidegger. Todavia, seria precipitado concluir que tal ausência terminológica é indício de uma remoção do conceito que está subjacente àquela designação. Em geral, parece-nos difícil imaginar uma efetiva expunção do conceito de afetividade da análise especulativa heideggeriana, como se, aos olhos do filósofo, o que foi elaborado na fase anterior da sua reflexão aparecesse como sendo não mais válido ou até mesmo incorreto. A improbabilidade de tal suposição é, de fato, confirmada pela auto-interpretação contida na Observação preliminar à $7^{a}$ edição de Ser e tempo (1953), na qual o filósofo alemão declara que "após um quarto de século [...] o seu caminho [ou seja, aquele inaugurado na primeira parte de Ser e tempo] permanece ainda hoje um caminho necessário"61. Tal afirmação é acompanhada, porém, pela advertência do autor de que as aquisições ganhas na primeira fase do seu pensamento devem ser submetidas a uma nova exposição. Portanto, deve-se esperar que no contexto da história do Ser os existenciais fundamentais elaborados em Ser e tempo sejam mantidos, mas parcialmente revisados ${ }^{62}$.

59 Cf. LÉVINAS. Philosophie, justice et amour, 1991, p. 135; La mauvaise conscience et l'inexorable, 1982, pp. 263-264; Ethique et infini, 1982, pp. 128-129.

60 Cf. em particular: LÉVINAS. Dieu et la philosophie, 1982, p. 103.

61 HEIDEGGER. Ser e tempo, 2006, p. 33.

62 Quem apontou para a importância de estudar a maneira como os existenciais elaborados em Ser e tempo são repensados por Heidegger no horizonte do pensamento da história do Ser, foi sobretudo: Von HERRMANN. Wege ins Ereignis, 1994, pp. 344-347. 
Com base na Observação citada, podem ser extraídas duas consequências relevantes. Por um lado, a tematização da afetividade conduzida em Ser e tempo deve permanecer um fulcro teórico também no contexto das Contribuições. Por outro, teremos que esperar, juntamente com a conservação de tal existencial, algum tipo de significativa revisão dele. Nesse sentido, a ausência do termo Befindlichkeit pode ser lida como uma medida precaucional adotada por Heidegger para evitar que o conceito denotado por esse termo seja assumido como perfeitamente equivalente ao sentido definido na ontologia fundamental e, portanto, para assinalar a modificação ocorrida. Em particular, a variação que se pode detectar no conceito de afetividade se conecta diretamente com aquele que é um dos principais aportes inovadores oferecidos pelas Contribuições: ou seja, com a descoberta do fato de que o estar-lançado do homem é proveniente do lançamento (Zuwurf) e da doação do $\operatorname{Ser}^{63}$. Se, já no âmbito da ontologia fundamental, a afetividade indicava um abrimento no qual o homem se encontra lançado, agora se torna explícito que a origem daquele estar-lançado é o acontecimento originário do Ser como movimento de doação ${ }^{64}$. A afetividade está lançada, porque indica a exposição passiva e a permeabilidade afetiva do homem em relação ao Ser, o qual, por sua vez, "lança-se", isto é, manifesta-se ao homem, criando a condição para que os entes possam ser experimentados. A afetividade representa, no horizonte das Contribuições, o medium originário por meio do qual o Ser se revela ao homem e assim o predispõe para a experiência da manifestação dos fenômenos ônticos.

Destacou-se, portanto, que o existencial da afetividade não é abandonado, mas apenas revisado à luz do lance do Ser. Se agora, por um lado, nós pretendemos defender a ideia de uma persistência de tal existencial no novo horizonte de pensamento heideggeriano, também não podemos, por outro, considerar como inválida e ultrapassada aquela distinção, estabelecida em 1927, entre a Stimmung e a Befindlichkeit, ou seja: entre a disposição ôntica e a sua premissa ontológica. Pode-se dizer que, no âmbito das Contribuições, a afetividade, entendida como constante exposição ao ser, é a condição necessária para que o homem possa experimentar tonalidades emotivas particulares, tanto em relação ao Ser como em relação aos entes, os quais chegam a manifestar-se somente graças ao acontecimento do Ser.

63 Cf. HEIDEGGER. Contribuições à filosofia, § 122, pp. 235-236; § 182, p. 296; § 194, p. $310 ; \S 255$, pp. 394-396.

64 Cf. id. ibid., § 269, p. 467: "O Ser des-loca, na medida em que se apropria do ser-aí em meio ao acontecimento. Esse des-locamento é uma afinação (Stimmen), sim, o rasgo originário do próprio elemento afinador" (trad. modificada). 
Com base nessas premissas, podemos agora nos concentrar na afirmação, contida no parágrafo 13 das Contribuições, segundo a qual a retenção (Verhaltenheit), isto é, uma tonalidade emotiva exemplar, é o fundamento do cuidado ${ }^{65}$. A Verhaltenheit, definida por Heidegger como a disposição afetiva fundamental da relação do homem com o Ser ${ }^{66}$, é elevada nas Contribuições à experiência e à conduta imprescindível dos pensadores do outro início, que assumem como própria a tarefa de relembrar aquilo que a metafísica deixou inexplorado. Considerando que a retenção, assim como qualquer tonalidade emotiva, sempre pressupõe a afetividade como sua condição de possibilidade, pode-se reformular a afirmação heideggeriana citada na ideia de que a própria afetividade é o fundamento último do cuidado.

Logo depois da menção da retenção enquanto fundamento da Sorge, Heidegger oferece um esclarecimento introdutório do conceito de cuidado, definindo-o como a "insistência (Inständigkeit) que suporta o a'́" ${ }^{67}$. Tal formulação é retomada no parágrafo 173 das Contribuições, onde Heidegger precisa que "o aí" indica "a clareira do Ser mesmo"68. Portanto, o cuidado está caracterizado como a insistência na verdade do Ser. Além dos ecos etimológicos certamente evocativos inerentes ao termo In-ständigkeit, interessa-nos esclarecer com precisão o que significa que o ser-aí seja aquilo que insista na verdade do Ser. Para entendê-lo, é preciso analisar os momentos estruturais do cuidado, noção que, como vimos, permanece válida nas Contribuições. No entanto, também para o conceito de cuidado temos que esperar uma reformulação parcial.

Já se mencionou que no horizonte das Contribuições a afetividade é pensada mais radicalmente como a abertura do homem ao acontecimento originário do Ser. Portanto, o momento do cuidado que em Ser e tempo correspondia à facticidade está novamente expresso nessa ideia da exposição afetiva ao Ser. Além disso, é possível detectar uma reformulação também dos outros dois momentos estruturais do cuidado: o momento da compreensão é repensado na ideia de fundação (Gründung) e aquele do ser-junto-a na ideia de abrigo (Bergung). Para o esclarecimento da primeira das duas reformulações, a referência textual privilegiada é oferecida pelo parágrafo 138 das Contribuições, no qual a fundação da verdade é explicitamente identificada com a compreensão do

65 Cf. id. ibid., § 13, p. 38.

66 Cf. HEIDEGGER. Grundfragen der Philosophie. Ausgewählte »Probleme« der »Logik«. GA 45, 1984, p. 2.

67 HEIDEGGER. Contribuições à filosofia, § 13, p. 38.

68 Id. ibid., § 173, p. 290 (trad. modificada). 
Ser $^{69}$. Quando, portanto, nas Contribuições Heidegger fala em fundação, ele tem em mente o compreender. A escolha do termo Gründen ao invés daquele de Verstehen, depende, provavelmente, do fato de que o primeiro designa, além da fundação humana, o fundar originário do próprio Ser. Adotando o mesmo verbo tanto em relação ao Ser como em relação ao homem, Heidegger pretende sublinhar a reciprocidade que existe entre o fundar ou o dar-se do Ser e a compreensão com a qual o homem cuida do Ser. A correspondência entre o Gründen do Ser e a fundação humana é ressaltada, de modo particular, no parágrafo 187 das Contribuições, no qual Heidegger descreve o esforço humano como um "deixar o fundamento se essenciar enquanto fundamento"70. Assim, fica evidente a proveniência do fundar humano da doação do Ser, a qual representa aquele $\varphi \alpha \imath{ }^{\prime} \mu \varepsilon v o v$ que se oferece como dado preliminar à dócil e não impositiva compreensão humana.

Voltando para a noção de abrigo, presente nas Contribuições ${ }^{71}$, ela nos parece ser a reformulação do momento do ser-junto-a da ontologia fundamental. Em particular, o abrigo é aquele esforço hermenêutico-criativo com o qual o homem transforma ou produz o ente como lugar privilegiado de manifestação do $\mathrm{Ser}^{72}$. O abrigo, que se realiza, segundo Heidegger, sobretudo nas formas eminentes da arte e do pensamento ${ }^{73}$, pode ser considerado uma modalidade do ser-junto-a, porque se configura como uma interpretação do ente à luz do Ser. Não devemos esquecer o fato de que, do ponto de vista de Heidegger, interpretar significa explicitar, isto é, trazer à luz aquilo que está latente e escondido, sem por isso levar tudo para a plena clareza. Consequentemente, pode-se afirmar que o abrigo identifica um movimento de interpretação, na medida em que traz à luz, na manifestatividade de um ente particular, a dinâmica inaparente do Ser. Este movimento interpretativo intrínseco ao abrigo encontra a sua máxima exemplificação na criação artística $^{74}$.

69 Cf. id. ibid., § 138, p. 255: "Assim, o com-preender do ser como (als) fundação de sua verdade é $[\ldots] "$.

70 Id. ibid., § 187, p. 299. Cf. HEIDEGGER. Beiträge zur Philosophie (Vom Ereignis). GA 65, 1994, § 187, p. 307: "den Grund als gründenden wesen lassen".

71 Cf. HEIDEGGER. Contribuições à filosofia, §§ 243-247, pp. 379-382.

72 Cf. id. ibid., § 123, p. 237: "[A guarda do homem] precisa erigir a verdade do Ser e abrigá-la no 'ente' mesmo, que, assim, desdobra pela primeira vez novamente 'inserindo no Ser e em seu estranhamento' a simplicidade encantadora de sua essência, ultrapassa toda maquinação [...]" (trad. modificada).

73 Cf. id. ibid., § 136, p. 252.

74 Cf. id. ibid., § 5, p. 23: "Mais fácil do que outros, o poeta encobre a verdade na imagem e a doa assim à visão para a conservação". 
Tendo presentes essas reformulações, voltemos, agora, para a afirmação do parágrafo 13 das Contribuições, segundo a qual a retenção, e, portanto, implicitamente a afetividade, é o fundamento do cuidado. Esta indicação implica, do nosso ponto de vista, que a afetividade não se limita a ser somente um momento da estrutura tripartida do cuidado: ela identifica o seu elemento principal, no qual os outros dois momentos, a fundação e o abrigo - isto é, as respectivas reformulações da compreensão e do ser-junto-a - estão fundados. Esta relação entre os momentos estruturais do cuidado se deixa inferir daquilo que Heidegger pensa e elabora nas Contribuições, e pode ser confirmada a partir dos seus escritos coevos e posteriores. De fato, os conteúdos teóricos ganhos nas Contribuições representam a chave interpretativa fundamental para acessar, na justa perspectiva, os escritos redigidos entre os anos trinta e o final dos anos sessenta ${ }^{75}$.

Quanto à fundação, dissemos que ela é baseada na doação do Ser, no fundar originário do próprio Ser. Pode-se deduzir do parágrafo 222 das Contribuições como este Gründen do Ser é, concretamente, realizado - parágrafo no qual a verdade do Ser que funda é definida como "a tonalidade afetiva que afina (stimmende Stimmung)" "76. Desta passagem textual resulta que o mesmo acontecimento do Ser não está isento de tonalidade afetiva, e que, por isso, afina o homem. Sem poder tratar de maneira detalhada da ideia, apenas aludida no parágrafo citado, segundo a qual o acontecimento da verdade do Ser seria o desdobramento de uma Stimmung originária ${ }^{77}$, o que nos interessa mais no contexto da presente discussão é a identidade que Heidegger estabelece entre a gründende Wahrheit do Ser e o "afinar". Isso implica que o sentido verbal da verdade, o seu "fundar", não é outro senão o "afinar". O Stimmen não é, portanto, um aspecto acessório do lançamento do Ser, mas define intrinsecamente o seu essenciar-se (wesen). O Ser se doa e se manifesta aos homens, na medida em que os afina. Não há dúvida de que esta ressonância do Ser no homem ocorre precisamente no nível da afetividade. É a Befindlichkeit o medium privilegiado que, por um lado, permite ao Ser afinar e tocar o homem e, por outro, torna o ser-aí capaz de sentir e acolher o fundar próprio da verdade. Se acima dissemos que a fundação humana se baseia no fundar próprio do Ser, agora vem à luz a caracterização afetiva desse movimento de doação. Sendo que o dar-se do

75 Isso é bem evidenciado por: Von HERRMANN. Die „Beiträge zur Philosophie ${ }^{e e}$ als hermeneutischer Schlüssel zum Spätwerk Heideggers, 1997.

76 HEIDEGGER. Contribuições à filosofia, § 222, p. 337.

77 Acerca disso, ver: PASQUALIN. Il fondamento "patico" dell'ermeneutico, 2015, pp. 456475 e $589-651$. 
Ser se desdobra essencialmente como um afinar e um manifestar-se "páthico", o acolhimento deste acontecimento originário por parte do homem ocorre na afetividade. Vislumbra-se, então, a origem afetiva da fundação humana: para poder compreender e fundar a verdade do Ser, o homem deve ter acolhido o dar-se desta verdade graças ao medium da sua afetividade. O contexto das Contribuições confirma assim como a fundação, enquanto momento estrutural do cuidado, é possibilitada pela afetividade.

Ao mesmo tempo, as Contribuições deixam claro que também o abrigo, nas suas várias modalidades, está enraizado na tonalidade emotiva fundamental e, por consequência indireta, na afetividade. Sobre isso Heidegger se pronuncia de maneira explícita no parágrafo 13, afirmando que a "retenção afina o respectivo instante fundante de um abrigo da verdade no ser-aí futuro do homem" "78. Uma exemplificação do fundar-se do abrigo na tonalidade afetiva é oferecida pela figura dos "vindouros" (die Zukünftigen), daqueles poucos e raros que executam a Bergung da verdade do Ser. Os vindouros são dispostos na tonalidade afetiva da retenção ${ }^{79}$, a qual, como já vimos, é a experiência do Ser e constitui, portanto, um pressuposto imprescindível para qualquer interpretação criativa no meio dos entes. No contexto das Contribuições, Heidegger reivindica com insistência esta raiz afetiva do abrigo, tendo em mente, sobretudo, aquela modalidade privilegiada de Bergung ${ }^{80}$ que consiste no pensar. Dessa maneira, Heidegger escreve, de forma muito clara, que a Grundstimmung é a condição de possibilidade do pensamento:

Todo pensar essencial exige que seus pensamentos e suas proposições sejam a cada vez cunhados de maneira nova como bronze a partir da tonalidade afetiva fundamental. Se a tonalidade afetiva permanecer de fora, então tudo é um falatório imposto de conceitos e cápsulas vocabulares $^{81}$.

78 HEIDEGGER. Contribuições à filosofia, § 13, p. 38.

79 Cf. id. ibid., § 252, p. 390: «Os que estão por vir, os responsáveis no ser-aí fundado pelo ânimo da retenção, à qual apenas cabe o ser (salto) como acontecimento apropriador, se apropriando deles em meio ao acontecimento e potencializando-os para o abrigo de sua verdade».

80 Ao pensar Heidegger parece atribuir uma certa preferência. Cf. id. ibid., § 120, p. 233: "São sempre poucos aqueles que chegam ao salto e esses chegam sempre por sendas diversas. Trata-se sempre das sendas da fundação criadora e sacrifical do ser-aí [...] O salto mais próprio e mais amplo é o salto do pensar".

81 Id. ibid., § 6, p. 25. 
O enraizamento do abrigo na afetividade, definido nas Contribuições, representa uma premissa teórica válida também para os escritos heideggerianos coevos e posteriores, explicitamente dedicados às questões da arte e do pensar. Nesses escritos emerge a ideia de que tanto a arte quanto o pensamento se originam de uma preliminar experiência do Ser que ocorre na tonalidade emotiva fundamental e que, portanto, é possibilitada pela afetividade. Pertencem à mesma fase de elaboração e redação do projeto especulativo das Contribuições tanto a preleção de 1934-1935 dedicada aos Hinos de Hölderlin, quanto o curso universitário sobre as Questões básicas de filosofia do semestre invernal de 1937-1938. Se, no primeiro contexto, Heidegger explicita como cada dizer poético está sempre afinado e predeterminado por uma tonalidade emotiva fundamental $^{82}$, no âmbito do curso de 1937-1938 o filósofo conduz uma fenomenologia da Grundstimmung do assombro (Erstaunen), para mostrar como ela impulsionou e sustentou o filosofar no mundo grego ${ }^{83}$. Assim, nos anos trinta já está delineada a estrutura especulativa em que se moverá também a reflexão heideggeriana posterior. Há escritos dos anos cinquenta e sessenta que ainda testemunham como Heidegger não tinha renunciado àqueles pressupostos teóricos definidos na decada dos trinta ${ }^{84}$.

Ao final do nosso percurso teórico, resulta mais uma vez não somente a coerência interna do caminho seguido por Heidegger, mas, sobretudo, a inalterada centralidade da afetividade. A nossa tentativa foi, em particular, pôr em relevo as analogias formais e a continuidade existente entre as duas fases do pensamento heideggeriano relativamente à questão da afetividade. Não somente o exame de Ser e tempo permite destacar o papel fundador da afetividade em relação aos outros dois momentos do cuidado, mas também as Contribuições à filosofia oferecem apoios textuais para confirmar a validade desta hipótese no então renovado horizonte especulativo do pensamento da história do Ser. Nas duas fases do percurso heideggeriano, a afetividade mantém a sua função privilegiada de modalidade de acesso ao ser e, por esta razão, representa uma passagem necessária ao longo da via pela qual o homem chega a realizar a sua dimensão hermenêutica.

82 Cf. HEIDEGGER. Hinos de Hölderlin, pp. 24 e 81.

83 Cf. HEIDEGGER. Grundfragen der Philosophie, pp. 153-180.

84 Cf. HEIDEGGER. Bemerkungen zu Kunst "Plastik" Raum, 1996: no começo do escrito Heidegger afirma que as obras de arte do mundo grego antigo eram afinadas pela disposição afetiva do pudor ( $\alpha i \delta \omega ́ \varsigma)$ ). Cf. HEIDEGGER. Was ist das - die Philosophie?, 1972, pp. 24-26: nessas páginas Heidegger esclarece como todo o filosofar sempre está fundado numa disposição afetiva e como, em particular, o assombro constitui, na época grega, a origem (⿳亠口八 $\chi \eta َ)$ do pensar. 
BORGES-DUARTE, I. A afectividade no caminho fenomenológico heideggeriano. Phainomenon. Revista de Fenomenologia, Lisboa, v. 24, 2012, pp. 43-62.

CAPUTO,A. Pensiero e affettività: Heidegger e le Stimmungen (1889-1928). Milano: Angeli, 2001.

Heidegger e le tonalità emotive fondamentali (1929-1946). Milano: Angeli, 2005.

CORBEIL, Y. Les «Grundstimmungen» et l'exercice du philosopher. Revue Philosophique de Louvain. Louvain-la-Neuve, v. 97, 1999, pp. 510-521.

CORIANDO, P.-L. Affektenlehre und Phänomenologie der Stimmungen: Wege einer Ontologie und Ethik des Emotionalen. Frankfurt a.M.: Klostermann, 2002.

DE ANGELIS, M. Per un'ontologia fenomenologica delle emozioni in Martin Heidegger. Discipline filosofiche, Macerata, v. 9, n. 2, 2000, pp. 183-226.

ESCUDERO, J.A. Heideggers Phänomenologie der Stimmungen. Zur welterschließenden Funktion der Angst, der Langweile und der Verlassenheit. Heidegger Studien, Berlin, v. 26, 2010, pp. 83-95.

FERREIRA, B. Stimmung bei Heidegger: Das Phänomen der Stimmung im Kontext von Heideggers Existenzialanalyse des Daseins. Dordrecht: Kluwer, 2002.

FINK-EITEL, H. Die Philosophie der Stimmungen in Heideggers »Sein und Zeit«. Allgemeine Zeitschrift für Philosophie, Stuttgart-Bad Cannstatt, v. 17, n. 3, 1992, pp. 27-44.

GANDER, H.-H. Grund- und Leitstimmungen in Heideggers „Beiträge zur Philosophie ${ }^{e e}$. Heidegger Studien, Berlin, v. 10, 1994, pp. 15-31.

HAAR, M. "Stimmung” et pensée. In: VOLPI, F. et al. (Ed.). Heidegger et l'idée de la phénoménologie. Dordrecht: Kluwer, 1988, pp. 265- 283.
HAN, B.-C. Heideggers Herz: Zum Begriff der Stimmung bei Martin Heidegger. München: Fink, 1996.

HEIDEGGER, M. Die Idee der Philosophie und das Weltanschauungsproblem. In: Zur Bestimmung der Philosophie. Gesamtausgabe. v. 56/57. Ed. B. Heimbüchel. Frankfurt a.M.: Klostermann, 1987, pp. 3-117.

. Grundbegriffe der aristotelischen Philosophie. Gesamtausgabe. v. 18. Ed. M. Michalski. Frankfurt a.M.: Klostermann, 2002.

. O Conceito de Tempo. Trad. Irene Borges-Duarte. Lisboa: Fim de Século, 2008 (2 $2^{\mathrm{a}}$ ed.).

. Sein und Zeit. Gesamtausgabe. v. 2. Ed. F.W. von Herrmann. Frankfurt a.M.: Klostermann, 1977. Trad. revisada Márcia Sá Cavalcante Schuback. Ser e tempo. Petrópolis: Vozes, 2006.

. O que é a Metafísica? Trad. Carlos Morujão. Lisboa: Relógio d'Água, 2004.

Die Grundbegriffe der Metaphysik. Welt Endlichkeit - Einsamkeit. Gesamtausgabe. v. 29/30. Ed. F.-W. von Herrmann. Frankfurt a.M.: Klostermann, 1983.

. Hinos de Hölderlin. Trad. Lumir Nahodil. Lisboa: Instituto Piaget, 2004.

. Beiträge zur Philosophie (Vom Ereignis). Gesamtausgabe. v. 65. Ed. F.-W. von Herrmann. Frankfurt a.M.: Klostermann, 1994 (2 ed.). Trad. Marco Antônio Casanova. Contribuições à filosofia (Do acontecimento apropriador). Rio de Janeiro: Via Verita, 2014.

. Grundfragen der Philosophie. Ausgewählte »Probleme« der »Logik«. Gesamtausgabe. v. 45. Ed. F.W. von Herrmann. Frankfurt a.M.: Klostermann, 1984.

. Was ist das - die Philosophie? Pfullingen: Neske, 1972. 
. Bemerkungen zu Kunst - Plastik - Raum. St. Gallen: Erker, 1996.

. Seminários de Zollikon. Trad. Gabriella Arnhold e Maria de Fátima de Almeida Prado. Petrópolis: Vozes, 2001.

HELD, K. Grundbestimmung und Zeitkritik bei Heidegger. In: PAPENFUSS, D.; PÖGGELER, O. (Ed.). Zur philosophischen Aktualität Heideggers. v. 1. Frankfurt a.M.: Klostermann, 1991, pp. 31-56.

HERRMANN von, F.-W. Wege ins Ereignis: Zu Heideggers »Beiträgen zur Philosophie«. Frankfurt a.M.: Klostermann, 1994.

Die „Beiträge zur Philosophie ${ }^{\text {ee }}$ als hermeneutischer Schlüssel zum Spätwerk Heideggers. In: HAPPEL, M. (Ed.). Heidegger neu gelesen. Würzburg: Königshausen und Neumann, 1997, pp. 75-86.

. Hermeneutische Phänomenologie des Daseins: Ein Kommentar zu „Sein und Zeit”. v. 3. Frankfurt a.M.: Klostermann, 2008.

KALARIPARAMBIL, T.S. Das befindliche Verstehen und die Seinsfrage. Berlin: Duncker \& Humblot, 1999.

LÉVINAS, E. Martin Heidegger et l'ontologie. In: En découvrant l'existence avec Husserl et Heidegger. Paris: Vrin, 1967 ( $2^{\mathrm{a}}$ ed.), pp. 53-76.

. L'ontologie dans le temporel. In: En découvrant l'existence avec Husserl et Heidegger, pp. 77-89.

. Dieu et la philosophie. In: De dieu qui vient a l'idée. Paris: Vrin, 1982, pp. 93-127.

. Notes sur le sens. In: De dieu qui vient a l'idée, pp. 231-257.

. La mauvaise conscience et l'inexorable. In: De dieu qui vient a l'idée, pp. 258-265.

. Éthique et infini. Paris: Fayard, 1982.

. Philosophie, justice et amour. In: Entre nous. Essais sur le penser-à-l'autre. Paris: Grasset, 1991, pp. 121-139.
. Transcendance et intellegibilité. Suivi d'un entretien. Genève: Éditions Labor et Fides, 1984.

MULHALL, S. Can There be an Epistemology of Moods? In: DREYFUS, H.; WRATHALL, M. (Ed.). Heidegger Reexamined. v. 4. New York: Routledge, 2002, pp. 33-52.

PASQUALIN, C. 'Der 'pathische' Grund des Hermeneutischen: Die ontologische Priorität der Befindlichkeit vor dem Verstehen". Heidegger Studies, Berlin, v. 31, 2015, pp. 129-151.

. Il fondamento "patico" dell'ermeneutico: affettività, pensiero e linguaggio nell'opera di Heidegger. Roma: Inschibboleth, 2015.

POCAI, R. Heideggers Theorie der Befindlichkeit: Sein Denken zwischen 1927 und 1933. Freiburg-München: Alber, 1996.

RODRÍGUEZ, A. Wahrheit und Befindlichkeit in der Fundamentalontologie. Würzburg: Königshausen und Neumann, 2003.

STENSTAD, G. Attuning and Transformation. Heidegger Studien, Berlin, v. 7, 1991, pp. 75-88.

VOLPI, F. Heidegger e Aristotele. Padova: Daphne, 1984.

WEBERMAN, D. Heidegger and the Disclosive Character of the Emotions. Southern Journal of Philosophy, Memphis, v. 34, n. 3, 1996, pp. 379-410. 